\title{
Grain Refinement Effect of Sb on Mg-5Y-3Sm-0.8Ca Alloy
}

\author{
Qing Zhang ${ }^{1,2, a}$, Jun Chen ${ }^{1,2}$, Quan-an $\mathrm{Li}^{1,2}$ \\ ${ }^{1}$ School of Materials Science and Engineering, Henan University of Science and Technology, \\ Luoyang 471023, China \\ ${ }^{2}$ Collaborative Innovation Center of Nonferrous Metals, Henan Province, Luoyang 471023, China \\ afoxzq@126.com
}

Keywords: magnesium alloy, $\mathrm{Sb}$, grain refinement, tensile strength.

Abstract: The grain refinement effect and related strengthening of alloying element $\mathrm{Sb}$ on as-cast Mg-5Y-3Sm-0.8Ca (wt.\%) alloy were investigated by microstructure observation, theoretic calculation and tensile tests. The results showed that $\mathrm{Mg}_{3} \mathrm{Sb}_{2}$ phase with high melting point is formed in the alloy after $\mathrm{Sb}$ addition. $\mathrm{Mg}_{3} \mathrm{Sb}_{2}$ phase can become the effective heterogeneous nucleation core of $\alpha-\mathrm{Mg}$ matrix, and refine the grain size and improve the microstructure of the alloy. It causes the grain refinement strengthening and enhances the tensile strength of the alloy. When the content of $\mathrm{Sb}$ addition is $0.5 \%$, the tensile strength of the alloy at room temperature is $234 \mathrm{MPa}$. It can be a basis for developing light structural magnesium materials.

\section{Introduction}

As the lightest metallic structural materials and "green engineering materials of 21 st century", magnesium alloys have the advantages of low density, high specific strength/stiffness, excellent damping effect and good recycling potential, and have been widely used in the fields of automobile manufacturing and electronic industry [1-4]. However, the mechanical properties of traditional magnesium alloys are unsatisfactory, which has been the main factor of limiting the further wider application of magnesium alloys. It is important and necessary to find a basis for developing light weight and high strength magnesium alloys.

Magnesium-RE (rare earth elements) alloys are interesting materials since they have excellent room and high temperature mechanical properties [5]. It is believed that $\mathrm{Y}$ is the most effective rare earth element to improve the properties of magnesium alloys [6]. Sm is one of important rare earth elements, and has the maximum solubility in $\mathrm{Mg}$ among light rare earth elements. It has been found that simultaneous addition of $\mathrm{Y}$ and $\mathrm{Sm}$ is significantly effective to increase the mechanical properties of magnesium alloys [7-10].

A recently developed as-cast $\mathrm{Mg}-5 \mathrm{Y}-3 \mathrm{Sm}-0.8 \mathrm{Ca}(\mathrm{wt} . \%)$ alloy exhibits attractive strength at room temperature [11]. In order to further enhance its strength properties, alloying element $\mathrm{Sb}$ is introduced in this work. The grain refinement effect and related strengthening of $\mathrm{Sb}$ on as-cast $\mathrm{Mg}-5 \mathrm{Y}-3 \mathrm{Sm}$ $0.8 \mathrm{Ca}$ alloy are investigated. It is hoped to provide a reference for the development of new type magnesium alloys.

\section{Experimental}

The compositions of tested alloy were designed as Mg-5Y-3Sm-0.8Ca-(0.5, 1.0)Sb (wt.\%). Pure metallic Mg (99.95 wt.\%), Sb (99.50 wt.\%) and Mg-25 wt.\% Y, Mg-25 wt.\% Sm and Mg-25 wt.\% Ca master alloys were used as raw materials.

All the raw materials were baked at $200^{\circ} \mathrm{C}$ to dry before the melting started. The alloys were melted in an induction furnace with an $\mathrm{Al}_{2} \mathrm{O}_{3}$ crucible under the protection atmosphere of 99 vol. $\% \mathrm{CO}_{2}$ and 1 vol. $\% \mathrm{SF}_{6}$. The melt was heated to $750^{\circ} \mathrm{C}$, and was poured into a metallic mold. The specimens were obtained after machining.

The phase analysis was performed by D8 Advance X-ray diffract meter (XRD) and Jade 5.0 software. The microstructure was observed and the grain sizes were measured by Olympus optical 
microscope $(\mathrm{OM})$. The planar mismatch degree was determined by theoretic calculation. The tensile tests were carried out at a strain rate of $1 \mathrm{~mm} / \mathrm{min}$ in an AG-I $250 \mathrm{kN}$ precision universal material test machine at room temperature.

\section{Results}

The XRD patterns of as-cast Mg-5Y-3Sm-0.8Ca-(0.5,1.0)Sb alloys are shown in Fig. 1. The results show that the microstructure of as-cast alloys consists of $\alpha-\mathrm{Mg}$ matrix, $\mathrm{Mg}_{24} \mathrm{Y}_{5}, \mathrm{Mg}_{41} \mathrm{Sm}_{5}, \mathrm{Mg}_{2} \mathrm{Ca}$ and $\mathrm{Mg}_{3} \mathrm{Sb}_{2}$. It can be seen that $\mathrm{Mg}_{3} \mathrm{Sb}_{2}$ phase with high melting point is formed in the alloy after $\mathrm{Sb}$ addition.

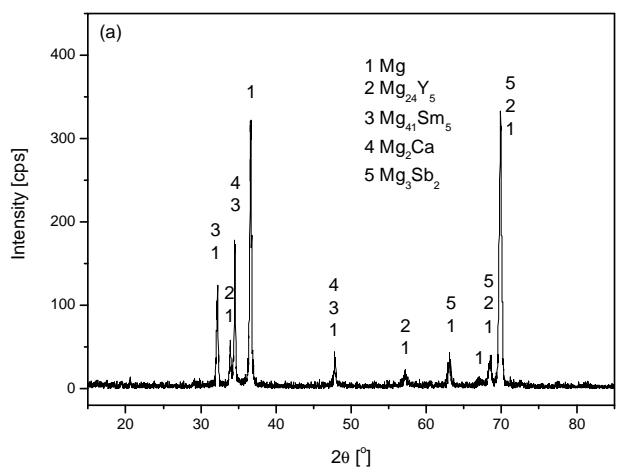

(a) $0.5 \% \mathrm{Sb}$

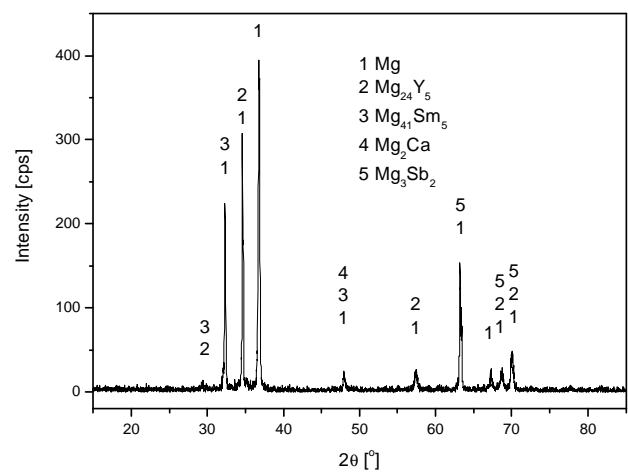

(b) $1.0 \% \mathrm{Sb}$

Fig. 1 XRD patterns of as-cast Mg-5Y-3Sm-0.8Ca-(0.5,1.0)Sb alloys

The microstructure of as-cast $\mathrm{Mg}-5 \mathrm{Y}-3 \mathrm{Sm}-0.8 \mathrm{Ca}-(0.5,1.0) \mathrm{Sb}$ alloys is shown in Fig. 2. It can be seen that $\mathrm{Sb}$ addition has an important effect on the microstructure of $\mathrm{Mg}-5 \mathrm{Y}-3 \mathrm{Sm}-0.8 \mathrm{Ca}$ alloy.

The microstructure of Mg-5Y-3Sm-0.8Ca-0.5Sb alloy is shown in Fig. 2a. It can be seen that there are a lot of secondary phases in the alloy when the content of Sb addition is $0.5 \%$. Most of the secondary phases are particles. They distribute homogeneously and dispersedly in the matrix. It can enhance the mechanical properties of the alloy.

The microstructure of Mg-5Y-3Sm-0.8Ca-1.0Sb alloy is shown in Fig. 2b. It can be seen that its microstructure is similar to that of the alloy with $0.5 \% \mathrm{Sb}$, but some secondary phases are larger in size and become big bulk shape. It may damage the mechanical properties of the alloy.

Compared with that of the alloy with $1.0 \% \mathrm{Sb}$, the microstructure of the alloy with $0.5 \% \mathrm{Sb}$ has two significant features: (1) The grains of the alloy are more uniform and their average sizes are decreased from $100 \mu \mathrm{m}$ to $60 \mu \mathrm{m}$. (2) The secondary phases are finer particles and their distributions are more uniform and dispersed. The microstructure will be helpful to the strength properties of the alloy.

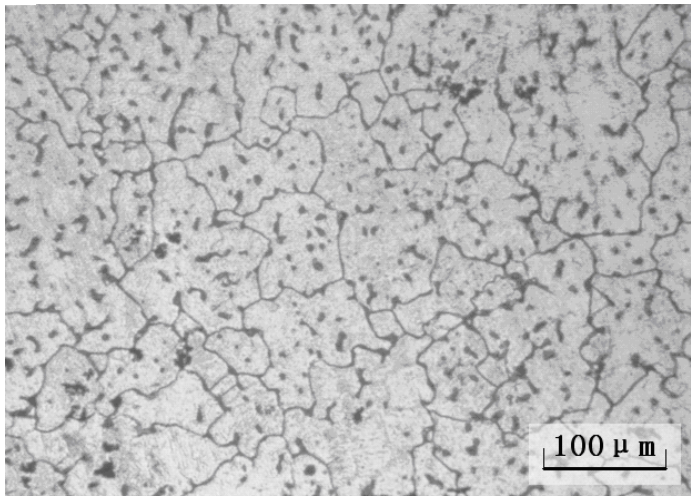

(a) $0.5 \% \mathrm{Sb}$

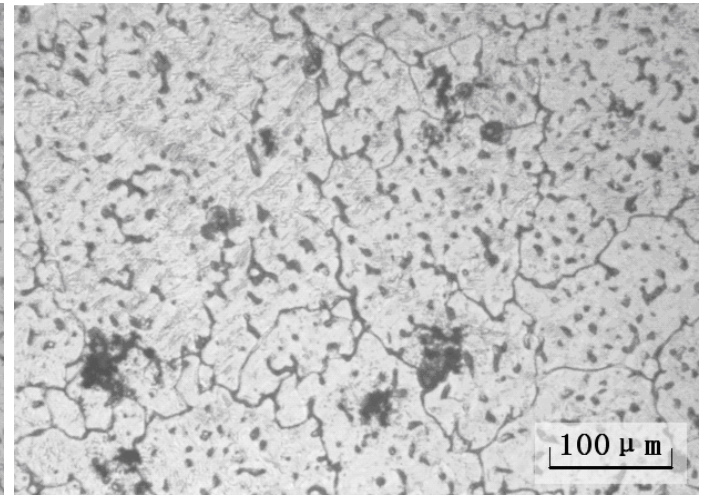

(b) $1.0 \% \mathrm{Sb}$

Fig. 2 Microstructure of as-cast $\mathrm{Mg}-5 \mathrm{Y}-3 \mathrm{Sm}-0.8 \mathrm{Ca}-(0.5,1.0) \mathrm{Sb}$ alloys

According to the work by Bramfitt [12], the mathematical model of the two-dimensional lattice mismatch degree is: 


$$
\delta_{(h k l) n}^{(h k l) s}=\sum_{i=1}^{3}\left[\left(\left|d_{[u v w]_{s}^{i}} \cos \theta-d_{[u v w]_{n}^{i}}\right| / d_{[u v w]_{n}^{i}}\right) / 3\right] \times 100 \%
$$

where $(h k l)_{\mathrm{s}}$ is the low-index plane of the matrix, and $[u v w]_{\mathrm{s}}$ is the low-index direction in $(h k l)_{\mathrm{s}} ;(h k l)_{\mathrm{n}}$ is the low-index plane in the nucleation core, and $[u v w]_{\mathrm{n}}$ is the low-index direction in $(h k l)_{\mathrm{n}} ; d_{[\mathrm{uvw}] \mathrm{s}}$ and $d_{[\mathrm{uvw} w \mathrm{n}}$ are the atomic space along $[u v w]_{\mathrm{s}}$ and $[u v w]_{\mathrm{n}} ; \theta$ is the angle between $[u v w]_{\mathrm{s}}$ and $[u v w]_{\mathrm{n}}$. Bramfitt's research showed that one criterion for heterogeneous nucleation is that the mismatch degree $\delta$ of nucleation plane should be less than $15 \%$.

Table 1 shows the matching parameters between the low-index plane of $\mathrm{Mg}_{3} \mathrm{Sb}_{2}$ and $\alpha-\mathrm{Mg} . \mathrm{Mg}_{3} \mathrm{Sb}_{2}$ is in hcp structure, $a=0.457 \mathrm{~nm}, c=0.723 \mathrm{~nm}$. And $\alpha-\mathrm{Mg}$ is also in hcp structure, $a=0.321 \mathrm{~nm}, c=0.521 \mathrm{~nm}$. By calculation, the mismatch degree $\delta$ is $5.4 \%, 6.9 \%$ and $6.7 \%$ respectively between $\mathrm{Mg}_{3} \mathrm{Sb}_{2}$ phase and $\alpha-\mathrm{Mg}$, which is less than $15 \%$. Therefore, $\mathrm{Mg}_{3} \mathrm{Sb}_{2}$ can become the heterogeneous nucleation core of $\alpha-\mathrm{Mg}$ matrix, and refine the grain size of as-cast $\mathrm{Mg}-\mathrm{Y}-\mathrm{Sm}-\mathrm{Ca}$ alloy.

Table 1 Calculation values of planar mismatch degree $\delta$ between $\mathrm{Mg}_{3} \mathrm{Sb}_{2}$ and $\alpha-\mathrm{Mg}$

\begin{tabular}{|c|c|c|c|c|c|c|}
\hline Matching interfaces & {$[h k l]_{s}$} & {$[h k l]_{n}$} & $\mathrm{~d}_{[\mathrm{uvw}] \mathrm{s}}[\mathrm{nm}]$ & $\mathrm{d}_{[\mathrm{uvw}] \mathrm{n}}[\mathrm{nm}]$ & $\theta\left[{ }^{\circ}\right]$ & $\delta$ \\
\hline \multirow{3}{*}{$(0001)_{\mathrm{Mg} 3 \mathrm{Sb} 2} \|(0001)_{\alpha-\mathrm{Mg}}$} & {$[\overline{1} 2 \overline{1} 0]$} & {$[\overline{1} 2 \overline{1} 0]$} & 0.963 & 0.914 & 0 & \multirow{3}{*}{$5.4 \%$} \\
\hline & {$[\overline{2} 110]$} & {$[\overline{2} 110]$} & 0.963 & 0.914 & 0 & \\
\hline & [1]120] & {$[\overline{1} 120]$} & 0.963 & 0.914 & 0 & \\
\hline \multirow{3}{*}{$(1 \overline{1} 00)_{\mathrm{Mg} 3 \mathrm{Sb} 2} \|(1 \overline{1} 00)_{\alpha-\mathrm{Mg}}$} & {$[\overline{11} 20]$} & [1120] & 0.963 & 0.914 & 0 & \multirow{3}{*}{$6.9 \%$} \\
\hline & {$[11 \overline{2} 1]$} & {$[11 \overline{2} 1]$} & 1.836 & 1.710 & 0 & \\
\hline & [0001] & [0001] & 1.563 & 1.446 & 0 & \\
\hline \multirow{3}{*}{$(11 \overline{2} 0)_{\mathrm{Mg} 3 \mathrm{Sb} 2} \|(11 \overline{2} 0)_{\alpha-\mathrm{Mg}}$} & {$[\overline{1} 100]$} & {$[\overline{1} 100]$} & 1.668 & 1.584 & 0 & \multirow{3}{*}{$6.7 \%$} \\
\hline & {$[\overline{1} 101]$} & [1]101] & 2.286 & 2.144 & 0 & \\
\hline & {$[0001]$} & [0001] & 1.563 & 1.446 & 0 & \\
\hline
\end{tabular}

The mechanical properties of as-cast Mg-5Y-3Sm-0.8Ca-(0.5,1.0)Sb alloys are shown in Table 2. It can be seen that, with the increase of Sb content, the tensile strength of the alloys at room temperature decreases. When the content of $\mathrm{Sb}$ addition is $0.5 \%$, the tensile strength is high, $234 \mathrm{MPa}$. When the content of $\mathrm{Sb}$ addition is $1.0 \%$, the tensile strength is lower, $214 \mathrm{MPa}$. Compared with that of the alloy with $1.0 \% \mathrm{Sb}$, the strength of the alloy with $0.5 \% \mathrm{Sb}$ is enhanced by $20 \mathrm{MPa}$. These are consistent with the results of microstructure observation. It also can be seen that the change of the elongation is similar to that of the tensile strength. $\mathrm{Mg}-5 \mathrm{Y}-3 \mathrm{Sm}-0.8 \mathrm{Ca}-0.5 \mathrm{Sb}$ alloy can be a basis for developing light structural magnesium materials.

Table 2 Mechanical properties of as-cast Mg-5Y-3Sm-0.8Ca-(0.5,1.0)Sb alloys

\begin{tabular}{ccc}
\hline Alloy & Tensile strength [MPa] & Elongation [\%] \\
\hline $0.5 \% \mathrm{Sb}$ & 234 & 4.0 \\
\hline $1.0 \% \mathrm{Sb}$ & 214 & 3.5 \\
\hline
\end{tabular}

In $\mathrm{Mg}$-Y-Sm-Ca-Sb alloys, $\mathrm{Mg}_{3} \mathrm{Sb}_{2}$ phase is one of the main strengthening phases at room temperature. It has a high thermal stability and its melting point is $1228{ }^{\circ} \mathrm{C}$. The solubility of alloying element $\mathrm{Sb}$ in $\mathrm{Mg}$ is very low and almost zero. In this work, the main reason for $\mathrm{Sb}$ to improve the mechanical properties of $\mathrm{Mg}-\mathrm{Y}-\mathrm{Sm}-\mathrm{Ca}$ alloys at room temperature should be attributed to the effective grain refinement strengthening.

It follows that $\mathrm{Sb}$ plays an important role in strengthening $\mathrm{Mg}-\mathrm{Y}-\mathrm{Sm}-\mathrm{Ca}-\mathrm{Sb}$ alloy. When the content of $\mathrm{Sb}$ addition is suitable, the mechanical properties of $\mathrm{Mg}-\mathrm{Y}-\mathrm{Sm}-\mathrm{Ca}-\mathrm{Sb}$ alloy can be improved by the grain refinement strengthening mechanism. When the content of $\mathrm{Sb}$ addition is excessive, the grain refinement strengthening effect may be impaired and the mechanical properties of $\mathrm{Mg}-\mathrm{Y}-\mathrm{Sm}-\mathrm{Ca}-\mathrm{Sb}$ alloy may be weakened. 


\section{Conclusions}

$\mathrm{Mg}_{3} \mathrm{Sb}_{2}$ phase with high melting point is formed in as-cast $\mathrm{Mg}-5 \mathrm{Y}-3 \mathrm{Sm}-0.8 \mathrm{Ca}$ alloy after $0.5 \%$ and $1.0 \% \mathrm{Sb}$ addition. $\mathrm{Mg}_{3} \mathrm{Sb}_{2}$ phase can become the effective heterogeneous nucleation core of $\alpha-\mathrm{Mg}$ matrix, and refine the grain size and improve the microstructure of $\mathrm{Mg}-5 \mathrm{Y}-3 \mathrm{Sm}-0.8 \mathrm{Ca}$ alloy. It causes the grain refinement strengthening and enhances the tensile strength of the alloy. When the content of $\mathrm{Sb}$ addition is $0.5 \%$, the tensile strength of the alloy at room temperature is $234 \mathrm{MPa}$. It can be a basis for developing light structural magnesium materials.

\section{Acknowledgement}

The financial support of the National Natural Science Foundation of China (NSFC-Henan Joint Fund of Personnel Training, No. U1404501) was gratefully acknowledged.

\section{References}

[1] Mordike B L, Ebert T. Magnesium: properties-applications-potential [J]. Materials Science and Engineering A, 2001, 302: 37-45.

[2] Luo A A. Recent magnesium alloy development for automotive powertrain applications [J]. Materials Science Forum, 2003, 419-422(1): 57-66.

[3] Yan Jingli, Sun Yangshan, Xue Feng, et al. Creep deformation mechanism of magnesium- based alloys [J]. Journal of Materials Science, 2008, 43: 6952-6959.

[4] Chen Zhenhua, Chen Jihua. A review: Hot topics on magnesium technology in China [J]. Frontier Materials Science of China, 2008, 2(1): 1-8.

[5] Mayumi Suzuki, Hiroyuki Sato, Kouich Maruyama, et al. Creep deformation behavior and dislocation substructures of Mg-Y binary alloys [J]. Materials Science and Engineering A, 2001, 319-321: 751-755.

[6] Mayumi Suzuki, Tsuyoshi Kimura, Junichi Koike, et al. Effects of zinc on creep strength and deformation substructures in Mg-Y alloy [J]. Materials Science and Engineering A, 2004, 387-389: 706-709.

[7] Li Daquan, Wang Qudong, Ding Wenjiang. Characterization of phases in Mg-4Y-4Sm-0.5Zr alloy processed by heat treatment[J]. Materials Science and Engineering A, 2006, 428: 295-300.

[8] Li Daquan, Wang Qudong, Ding Wenjiang. Precipitate phases in the Mg-4Y-4Sm-0.5Zr alloy [J]. Journal of Alloys and Compounds, 2008, 465: 119-126.

[9] Zhang Qing, Li Quan-an, Jing Xiaotian, et al. Microstructure and mechanical properties of Mg-10Y-2.5Sm alloy[J]. Journal of Rare Earths, 2010, 28(Spec. Issue): 375-377.

[10]Li Quan-an, Zhang Qing, Wang Yaogui, et al. Effects of Sm addition on microstructure and mechanical properties of a Mg-10Y alloy [J]. China Foundry, 2014, 11(1): 28-32.

[11]Zhang Qing, Li Quan-an, Chen Jun, et al. Microstructure and mechanical properties of Mg-Y-Sm-Ca alloys [J]. Applied Mechanics and Materials, 2014, 488: 197-200.

[12]Bramfitt B L. Effect of carbide and nitride additions on the heterogeneous nucleation behavior of liquid iron[J]. Metallurgical and Materials Transactions B, 1970, 1(7): 1987-1995. 